\title{
Displacement of Vitamin D Receptor Is Related to Lower Histological Grade of Endometrioid Carcinoma
}

\author{
HYO JUNG AN ${ }^{1}$ and DAE HYUN SONG ${ }^{1,2,3}$ \\ ${ }^{1}$ Department of Pathology, Gyeongsang National University Changwon Hospital, Changwon, Republic of Korea; \\ ${ }^{2}$ Gyeongsang National University School of Medicine, Jinju, Republic of Korea; \\ ${ }^{3}$ Gyeongsang Institute of Health Science, Jinju, Republic of Korea
}

\begin{abstract}
Background/Aim: Vitamin D analogs have a protective effect on carcinogenesis in humans. Since vitamin $D$ receptor (VDR) is detected in many histotypes of cancer, this study evaluated the role of VDR expression in endometrioid carcinoma. Materials and Methods: Tumor samples were collected from 60 patients who had undergone surgery, and the pattern of VDR expression assessed in tissue microarray (TMA) blocks of tumor samples. When VDR expression in the cytoplasm was higher than that in the nucleus, this was noted as 'displacement'. Using statistical analysis, the relationship between VDR expression and clinicopathological factors was evaluated. Results: Immunohistochemical staining of nuclear VDR was as follows: Negative: 32 (53.3\%); mild: 13 (21.7\%); moderate: 14 (23.3\%); strong: 1 (1.7\%). For cytoplasmic VDR expression: Negative: 2 (3.3\%); mild: 19 (31.7\%); moderate: 31 (51.7\%); strong: 7 (11.7\%). VDR displacement was found in $42(70 \%)$ cores. VDR displacement was significantly positively correlated with endometrioid carcinoma having lower histological grade $(1, p=0.03)$. Conclusion: Displacement of VDR was significantly correlated with lower histological grade. Clinicians might be able to predict prognosis and decide therapies related to vitamin $D$ analogs using this remarkable biomarker for endometrial carcinoma.
\end{abstract}

Endometrial adenocarcinoma is the third most common malignancy of the female genital tract, ranking after cervix and ovarian cancer, and its incidence is on the rise. Prognosis can vary depending on histological type, the most common being endometrioid adenocarcinoma, which constitutes approximately $80 \%$ of all cases. Among these, surgical stage $1 \mathrm{~b}$ is the most common, followed by stage $1 \mathrm{c}$. Surgery

Correspondence to: Dae Hyun Song, M.D., Department of Pathology, Gyeongsang National University School of Medicine, 79 Gangnam-ro, Jinju-si, Gyeongsangnam-do, Republic of Korea. Tel: +82 552143150, Fax: +82 552143174, e-mail: golgy@ hanmail.net

Key Words: Carcinoma, displacement, endometrioid, vitamin D receptor. remains the primary treatment, with radiation therapy as the main adjunctive therapy, even in early-stage cancer. However, radiation therapy has been suggested not to improve survival in early-stage cancer (stage Ia, Ib, grade 1, 2) (1). There have also been many attempts to use preoperative hormonal therapies for cancer, including prostate and breast cancer (2).

Vitamin D receptor (VDR), a member of the nuclear receptor superfamily mainly located in the nucleus, plays a central role in the biological actions of vitamin D (3). It regulates the expression of various genes associated with calcium and phosphate homeostasis, cellular proliferation, differentiation, and immune responses (4). In addition, analogs of 1,25-dihydroxyvitamin $\mathrm{D}\left(1,25-(\mathrm{OH})_{2} \mathrm{D}\right)$ are known to have a protective effect on carcinogenesis of prostate and breast cancer by altering androgen metabolism (prostate) or estrogen metabolism (breast) (2); however, their intrinsic mechanisms of action against cancer cells remain to be understood. For breast cancer, which is greatly affected by female hormones, studies on VDR are still continuing, and therapies related to vitamin D analog use are being reported $(5,6)$. However, in the case of endometrial cancer, which is also significantly affected by female hormones, studies on VDR are sparse (7-9). Therefore, we investigated VDR expression in endometrioid carcinoma and identified its pathological characteristics.

\section{Materials and Methods}

Patients and clinicopathological information. Tumor samples were collected from 60 patients who had undergone surgical resection for endometrioid carcinoma at the Gyeongsang National University Hospital (Jinju, Korea) between January 2002 and December 2009. These specimens were staged using the eighth edition of American Joint Committee on Cancer (AJCC) (10) and TNM Classification of Malignant Tumors. We obtained clinical information by reviewing electronic medical charts. This study was approved by the Institutional Review Board of Gyeongsang National University Hospital (GNUH-2019-03-009) and was conducted in accordance with the principles embodied in the Declaration of Helsinki. 
Tissue microarray and immunohistochemical staining. Representative hematoxylin and eosin-stained glass slides, containing intratumoral lesions from 60 endometrial cancer specimens, were selected for analysis. To obtain the tissue sample for staining, a 3-mm core was extracted from the front of the invasive tumor onto a representative paraffin block and transplanted into the recipient tissue microarray (TMA) block. Immunohistochemical staining was performed on $4-\mu \mathrm{m}$ sections of the TMA block samples. Once attached to glass slides, the sections were de-paraffinized, rehydrated, and incubated in $3 \%$ hydrogen peroxide for $10 \mathrm{~min}$ to block endogenous peroxidase activity, which can result in non-specific background staining. Thereafter, sections were heated in a microwave oven $(700 \mathrm{~W})$ for $20 \mathrm{~min}$ in $10 \mathrm{mM}$ citrate buffer (pH 6.0). After incubation with Ultra $\mathrm{V}$ block (Lab vision Corporation, Fremont, CA, USA) for $7 \mathrm{~min}$ at room temperature to block background staining, slides were incubated with a primary monoclonal antibody specific to VDR (1:100 dilution, ab8756; Abcam, Cambridge, MA, USA), and an ultraView Universal DAB detection kit was used (760-500; Ventana, Tuscon, AZ, USA) for visualization, according to the manufacturer's recommendations. 3, 3'-Diaminobenzidine was used to detect the protein, and the sections were then counterstained with hematoxylin.

Identification of VDR expression. The immunohistochemical staining pattern of VDR was evaluated for each of the 60 cores on the TMA blocks. The intensity of VDR expression in tumor cells was graded as per a four-tier system: Negative: 0, mild: 1+; moderate: $2+$; strong: $3+$. When VDR expression in the cytoplasm was higher than that in the nucleus, this was noted as 'displacement'. Small intestine was used as the positive control.

Statistical analysis. The relationship of VDR expression with clinicopathological characteristics, including age, T-stage, and histological grade, was assessed using chi-squared test. In addition, the relationship between histological grade and VDR displacement was evaluated by Pearson's chi-square test. Associations with $p$-values less than 0.05 were regarded as statistically significant. Analyses were performed using IBM SPSS ver. 24.0 (IBM Corp., Armonk, NY, USA).

\section{Results}

Clinicopathological information of the patients. Clinicopathological information of the 60 patients with endometrioid carcinoma is summarized in Table I. The mean age of patients was 51 years (range $=35-78$ years). $\mathrm{T}$-Stage in most cases $1 \mathrm{a}$ (71.7\%) and with respect to histological grade, 40 (66.7\%) were grade 1 .

Characteristic features of VDR expression and VDR displacement. Immunohistochemical staining of nuclear VDR revealed most cases to be negatively to mildly stained $(75 \%)$. Although VDR is commonly present in the nucleus, we found its expression both in the nucleus (Figure 1A) and cytoplasm (Figure 1B). Cytoplasmic VDR expression was moderate to strong in two-thirds of cases. VDR displacement was found in $42(70 \%)$ cores. The frequency of displacement was significantly increased in samples with low histological grade (grade $1 ; p=0.03$ ), compared to those with higher histological grade.
Table I. Clinicopathological information of patients with endometrioid carcinoma and vitamin D receptor (VDR) expression.

\begin{tabular}{lc}
\hline Variable & Value \\
\hline Age, years & \\
Mean (range) & $51(35-78)$ \\
T-Stage, $\mathrm{n}(\%)$ & \\
1a & $43(71.7 \%)$ \\
$1 \mathrm{~b}$ & $12(20)$ \\
2 & $3(5)$ \\
$3 \mathrm{a}$ & $1(1.7)$ \\
$3 \mathrm{~b}$ & $1(1.7)$ \\
Histological grade, $\mathrm{n}(\%)$ & \\
1 & $40(66.7)$ \\
2 & $15(25)$ \\
3 & $5(8.3)$ \\
VDR & \\
Nuclear, $\mathrm{n}(\%)$ & $32(53.3)$ \\
Negative & $13(21.7)$ \\
Mild & $14(23.3)$ \\
Moderate & $1(1.7)$ \\
Strong & \\
Cytoplasmic, $\mathrm{n}(\%)$ & $2(3.3)$ \\
Negative & $19(31.7)$ \\
Mild & $31(51.7)$ \\
Moderate & $7(11.7)$ \\
Strong & $1(1.7)$ \\
Not informative** & $42(70)$ \\
VDR displacement, $\mathrm{n}(\%)^{*}$ & 60 \\
& \\
& \\
&
\end{tabular}

*Higher expression in the cytoplasm than the nucleus. **Tissue loss in the tissue microarray block.

Table II. The relationship between vitamin D receptor (VDR) displacement and histological grade in endometrioid carcinoma.

\begin{tabular}{lccc}
\hline & \multicolumn{3}{c}{ VDR displacement, $\mathrm{n}$} \\
\cline { 2 - 4 } & No & Yes & Total \\
\hline Histological grade & & & \\
1 & 8 & 32 & 40 \\
2,3 & 9 & 10 & 19 \\
\hline Total & 17 & 42 & $p=0.03$ \\
\hline
\end{tabular}

\section{Discussion}

Vitamin D belongs to the non-steroid receptor family that acts through genomic and non-genomic pathways. The classical genomic response is mediated through VDR, a member of the nuclear receptor superfamily (3). VDRs are present in more than 30 tissues, including the intestine, kidney, bone, ovary, breast, and prostate $(11,12)$. They play a central role in the biological actions of vitamin $D$. In kidneys, 25- 
A

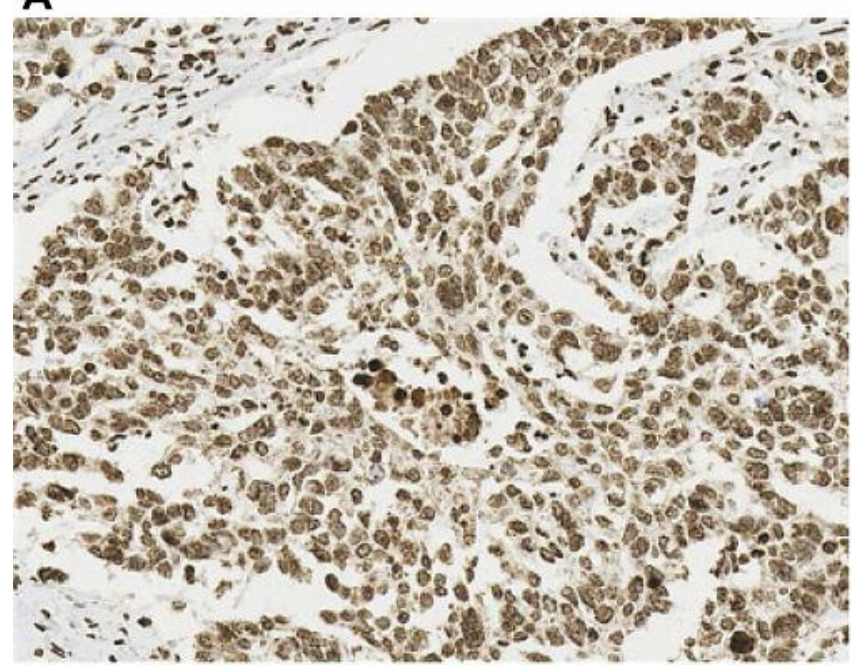

B

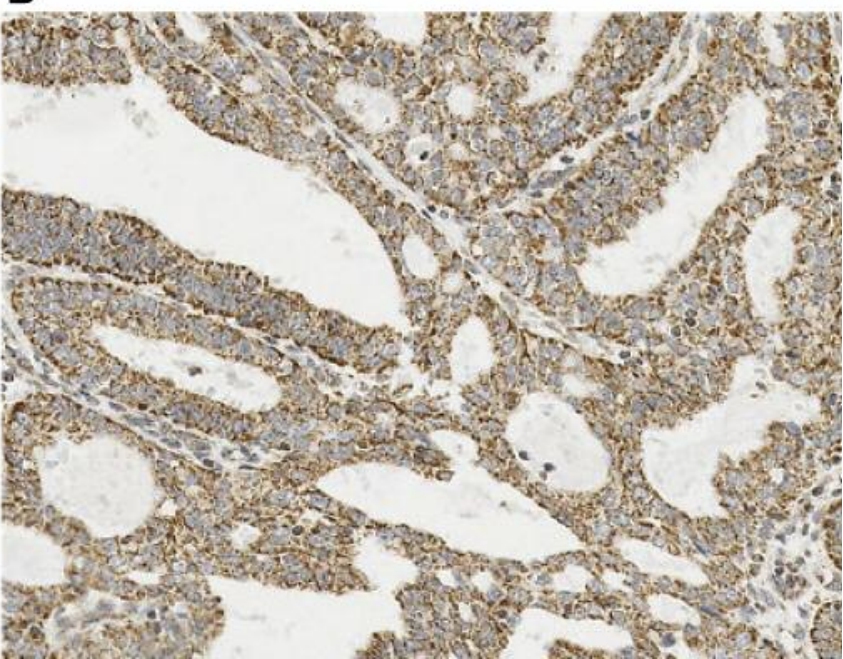

Figure 1. Immunohistochemical findings of staining for vitamin D receptor (VDR). A: Diffuse nuclear staining pattern of VDR expression in endometrioid cancer cells $(\times 200)$. B: Example of VDR expression in the cytoplasm being higher than that in the nucleus. This is referred to in the text as 'displacement' $(\times 200)$.

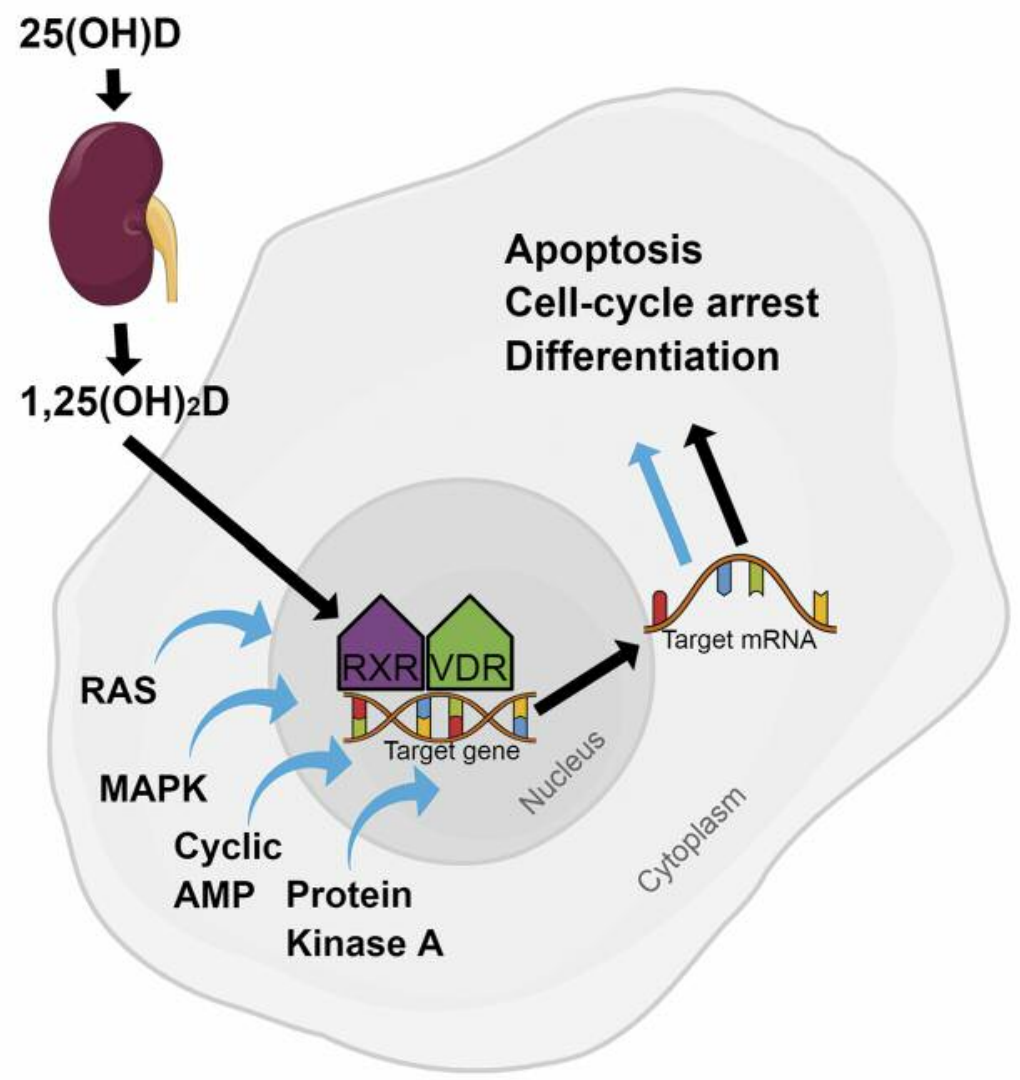

Figure 2. The role of vitamin $D$ receptor $(V D R)$ in $m R N A$ transcription. In kidneys, $25(\mathrm{OH})$-vitamin $D[25(\mathrm{OH}) \mathrm{D}]$ is converted to $1,25(\mathrm{OH})_{2}$ vitamin $D\left[1,25(\mathrm{OH})_{2} \mathrm{D}\right]$ using the enzyme 1-alpha-hydroxylase. When $1,25(\mathrm{OH})_{2} \mathrm{D}$ enters the nucleus, it binds to the VDR to form a heterodimer with the retinoid-X receptor $(R X R)$. This complex, in turn, binds to the hormone-response elements of the target gene to increase mRNA transcription (classical pathway; black arrow). In cooperation with the cytoplasmic pathway (blue arrow: RAS, mitogen-activated protein kinase (MAPK), cyclic $A M P$, and protein kinase A), VDR moves the target gene to the cytoplasm to initiate apoptosis, cell-cycle arrest, and cell differentiation. 
hydroxyvitamin $\mathrm{D}[25(\mathrm{OH}) \mathrm{D}]$, the primary circulating form of vitamin $\mathrm{D}$, is converted to $1,25(\mathrm{OH})_{2} \mathrm{D}$, the most active form of vitamin $\mathrm{D}$, using the enzyme 1-alpha-hydroxylase. When $1,25(\mathrm{OH})_{2} \mathrm{D}$ enters the nucleus, it binds to VDR to form a heterodimer with the retinoid-X receptor. This complex further binds to hormone-response elements of the target gene to increase its mRNA transcription (Figure 2). Thereafter, mRNA moves to the cytoplasm to synthesize the specific protein. VDR regulates the expression of various genes associated with homeostasis of calcium and phosphate, cell proliferation, cell differentiation, and the immune system (4). Additionally, it also has an effect on tumorigenesis through the extracellular scavenger system, chemotaxis, macrophage response, apoptosis, and angiogenesis (5).

There are contradictory reports of the effect of VDR on endometrial cancer. Tagliabue et al. studied the relationship between polymorphisms of genes encoding VDR ( $G C$ rs7041 and rx4588) and cancer in various sites, including the endometrium, and found no significant association (5). In contrast, using animal models, Yu W et al. showed that vitamin D intake prevented an increase in obesity-induced endometrial cancer (9). Parikh et al. reported that since 1,25vitamin D concentrations decrease with increasing adiposity, elevation in 1,25-vitamin D might not be an important hormonal mechanism maintaining or causing obesity in adults (13). Finally, Agic et al. reported that VDR is expressed in both pathological and non-pathological endometrial tissues, and its expression levels in endometrial cancer were found to be significantly higher than in normal endometrial tissue. In their study, the immunohistochemical findings showed strong positive staining of VDR in cases with endometriosis and endometrial cancer, the most intensive staining patterns being seen in epithelial cells of the endometrium. Additionally, there was significantly higher 1-alpha-hydroxylase expression in the endometrium in cases with endometriosis compared to that in healthy controls (14). Similarly, using two different microarray platforms, Huvila et al. showed that in poorly differentiated endometrioid adenocarcioma, VDR is overexpressed compared to that in well- or moderately- differentiated adenocarcinomas (15).

In our study, both nuclear and cytoplasmic staining of VDR showed its expression to be lower in normal endothelial cells. In endometrial cancer cells, VDR displacement was found in 42 (70\%) cores, being significantly increased in samples with lower histological grade $(1, p=0.03)$, compared to that in high grade.

Displacement of VDR expression may exhibit unexpected consequences. According to a previous study by Agic et al., vitamin D regulates not only the classical genomic pathway, but also various cytoplasmic pathways that may cooperate with the former ones to activate VDR (14). Cytoplasmic pathways include RAS, mitogen-activated protein kinase (MAPK), protein lipase A and prostaglandins, cyclic AMP, and protein kinase $\mathrm{A}$, and phosphatidylinositol 3, which ultimately affect cellular growth, cell differentiation, and apoptosis (Figure 2) (14). We conclude that displacement of VDR expression may be affected by one of the cytoplasmic pathways to co-activate VDR and exhibits a protective effect against a more aggressive phenotype (higher histologic grade) in endometrioid carcinoma. Studies covering larger populations, targeting the mechanism of VDR expression in endometrial cancer are recommended to discover whether it has a predictive role.

To date, the International Federation of Gynecology and Obstetrics (FIGO) grading system has been one of the most powerful prognostic factors for clinical monitoring and prognosis prediction in endometrioid carcinoma. According to the FIGO grading system, grade $1: \leq 5 \%$ of non-squamous or non-morular solid growth pattern; grade 2: 6-50\% of nonsquamous or non-morular solid growth pattern; grade $3:>50 \%$ of non-squamous or non-morular solid growth pattern (16). In evaluating FIGO grading, inter-observer discrepancies may occur, since notable nuclear atypia, inappropriate for the architectural grade, raises the grade of a grade 1 or 2 tumor by one level. Therefore, many researchers have used alternative methods, such as immunohistochemical staining, genetic molecular tests, and other two-tier grading systems (17).

Specimens obtained from dilatation and curettage are too small and limited to decide on FIGO grading accurately, since the proportion of solid component cannot be measured with a representative section. Displacement of VDR, in contrast, can be evaluated by immunohistochemical staining of just a small part of the section.

Vitamin D administration to cancer cells has been evaluated thoroughly, both at the cellular level (18) as well as at human tissue level (2). Administration of vitamin D analog to cultured breast cancer cells activated vitamin D-mediated metabolic processes. In addition, many studies have suggested the administration of vitamin D compounds is effective in the pre-operative period of patients with prostate cancer $(2,19$ 22). Herein, we suggest that since the displacement of VDR appears to reflect the FIGO grading system well, evaluating a pre-operative biopsy with VDR immunohistochemical staining would potentially be important for clinicians to decide whether vitamin $\mathrm{D}$ analogs might be needed by patients with earlystage endometrioid carcinoma.

In conclusion, VDR is expressed in pathological endometrial tissue, and its displacement is significantly correlated with low histological grade in FIGO grading of endometrioid carcinomas. Clinicians might be able to predict prognosis and use this remarkable biomarker to decide therapies related to vitamin D analogs that might be needed in endometrial carcinoma.

\section{Conflicts of Interest}

The Authors declare no conflicts of interest in regard to this study. 


\section{Authors' Contributions}

Conceptualization: HJA, DHS; Data curation: HJA; Formal analysis: HJA; Writing: HJA, DHS; Review and editing: DHS.

\section{References}

1 Creasman WT, Odicino F, Maisonneuve P, Quinn MA, Beller U, Benedet JL, Heintz AP, Ngan HY and Pecorelli S: Carcinoma of the corpus uteri. FIGO 26th Annual Report on the Results of Treatment in Gynecological Cancer. Int J Gynaecol Obstet 95(Suppl 1): S10543, 2006. PMID: 17161155. DOI: 10.1016/ S0020-7292(06)60031-3

2 Trump DL: Calcitriol and cancer therapy: A missed opportunity. Bone Reports 9: 110-119, 2018. PMID: 30591928. DOI: 10. 1016/j.bonr.2018.06.002

3 Mangelsdorf DJ, Thummel C, Beato M, Herrlich P, Schütz G, Umesono K, Blumberg B, Kastner P, Mark M, Chambon P and Evans RM: The nuclear receptor superfamily: the second decade. Cell 83(6): 835-839, 1995. PMID: 8521507.

4 Wang Y, Zhu J and DeLuca HF: Where is the vitamin D receptor? Arch Biochem Biophys 523(1): 123-133, 2012. PMID: 22503810. DOI: 10.1016/j.abb.2012.04.001

5 Tagliabue E, Raimondi S and Gandini S: Meta-analysis of vitamin D-binding protein and cancer risk. Cancer Epidemiol Biomarkers Prev 24(11): 1758-1765, 2015. PMID: 26364161. DOI: $10.1158 / 1055-9965 . E P I-15-0262$

6 Giovannucci E: The epidemiology of vitamin D and cancer incidence and mortality: a review (United States). Cancer Causes Control 16(2): 83-95, 2005. PMID: 15868450. DOI: 10.1007/ s10552-004-1661-4

7 Hwang J, Wang T, Lee K, Joo J and Lee H: Vitamin D binding protein plays an important role in the progression of endometriosis. Int J Mol Med 32(6): 1394-1400, 2013. PMID: 24064663. DOI: $10.3892 / \mathrm{ijmm} .2013 .1506$

8 Bergada L, Pallares J, Arcidiacono MV, Cardus A, Santacana M, Valls J, Cao G, Fernàndez E, Dolcet X, Dusso AS and MatiasGuiu X: Role of local bioactivation of vitamin D by CYP27A1 and CYP2R1 in the control of cell growth in normal endometrium and endometrial carcinoma. Laboratory Investigation 94(6): 608, 2014. PMID: 24732451. DOI: 10.1038/ labinvest.2014.57

9 Yu W, Cline M, Maxwell LG, Berrigan D, Rodriguez G, Warri A and Hilakivi-Clarke L: Dietary vitamin D exposure prevents obesity-induced increase in endometrial cancer in Pten $^{+/-}$mice. Cancer Prev Res 3(10): 1246-1258, 2010. PMID: 20858763. DOI: 10.1158/1940-6207.CAPR-10-0088

10 Amin MB, Edge S, Greene F, Byrd DR, Brookland RK, Washington MK, Gershenwald JE, Compton CC, Hess KR, Sullivan DC, Jessup JM, Brierley JD, Gaspar LE, Schilsky RL, Balch CM, Winchester DP, Asare EA, Madera M, Gress DM and Meyer LR: AJCC Cancer Staging Manual, Eighth Edition. Springer, New York, 2017.

11 Berger U, Wilson P, McClelland RA, Colston K, Haussler MR, Pike JW and Coombes RC: Immunocytochemical detection of 1,25-dihydroxyvitamin $\mathrm{D}$ receptors in normal human tissues. J Clin Endocrinol Metab 67(3): 607-613, 1988. PMID: 2842365. DOI: $10.1210 /$ jcem-67-3-607

12 Holick MF: Vitamin D: A millenium perspective. J Cell Biochem 88(2): 296-307, 2003. PMID: 12520530. DOI: 10.1002/jcb. 10338
13 Parikh SJ, Edelman M, Uwaifo GI, Freedman RJ, Semega-Janneh M, Reynolds J and Yanovski JA: The relationship between obesity and serum 1,25-dihydroxy vitamin D concentrations in healthy adults. J Clin Endocrinol Metab 89(3): 1196-1199, 2004. PMID: 15001609. DOI: $10.1210 /$ jc.2003-031398

14 Agic A, Xu H, Altgassen C, Noack F, Wolfler MM, Diedrich K, Friedrich M, Taylor RN and Hornung D: Relative expression of 1,25-dihydroxyvitamin $\mathrm{D}_{3}$ receptor, vitamin $\mathrm{D} 1 \alpha$-hydroxylase, vitamin D 24-hydroxylase and vitamin D 25-hydroxylase in endometriosis and gynecologic cancers. Reprod Sci 14(5): 486497, 2007. PMID: 17913968. DOI: 10.1177/1933719107304565

15 Huvila J, Brandt A, Rojas CR, Pasanen S, Talve L, Hirsimäki P, Fey V, Kytömäki L, Saukko P, Carpén O, Soini JT, Grénman S and Auranen A: Gene expression profiling of endometrial adenocarcinomas reveals increased apolipoprotein E expression in poorly differentiated tumors. Int J Gynecol Cancer 19(7): 1226-1231, 2009. PMID: 19823059. DOI: 10.1111/IGC.0b 013e3181b33be0

16 Creaseman W: Revised FIGO staging for carcinoma of the endometrium. Int J Gynecol Obstet 105(2): 109, 2009. PMID: 19345353. DOI: 10.1016/j.ijgo.2009.02.010

17 Kim MH, Song DH, Ko GH, Lee JH, Kim DC, Yang JW, Lee HI, An HJ and Lee JS: Myoferlin expression and its correlation with FIGO histologic grading in early-stage endometrioid carcinoma. J Pathol Transl Med 52: 93-97, 2018. PMID: 29554794. DOI: 10.4132/jptm.2017.11.29

18 Zheng W, Duan B, Zhang Q, Ouyang L, Peng W, Qian F Wang Y and Huang S: Vitamin D-induced vitamin D receptor expression induces tamoxifen sensitivity in MCF-7 stem cells via suppression of Wnt/ $\beta$-catenin signaling. Biosci Rep 38(6): BSR20180595, 2018. PMID: 30314996. DOI: 10.1042/BSR201 80595

19 Doherty D, Dvorkin SA, Rodriguez EP and Thompson PD: Thompson Vitamin D receptor agonist EB1089 is a potent regulator of prostatic "intracrine" metabolism. Prostate 74: 273285, 2014. PMID: 24242708. DOI: 10.1002/pros.22748

20 Seo YK, Mirkheshti N, Song CS, Kim S, Dodds S, Ahn SC, Christy B, Mendez-Meza R, Ittmann MM, Abboud-Werner S and Chatterjee B: SULT2B1b sulfotransferase: Induction by vitamin $\mathrm{D}$ receptor and reduced expression in prostate cancer. Mol Endocrinol 27: 925-939, 2013. PMID: 23579488. DOI: 10.1210/ me.2012-1369

21 Maguire O, Pollock C, Martin P, Owen A, Smyth T, Doherty D, Campbell MJ, McClean S and Thompson P: Regulation of CYP3A4 and CYP3A5 expression and modulation of "intracrine" metabolism of androgens in prostate cells by liganded vitamin D receptor. Mol Cell Endocrinol 364: 54-64, 2012. PMID: 22939842. DOI: 10.1016/j.mce.2012.08.007

22 Going CC, Alexandrova L, Lau K, Yeh CY, Feldman D and Pitteri SJ: Vitamin D supplementation decreases serum 27hydroxycholesterol in a pilot breast cancer trial. Breast Cancer Res Treat 167: 797-802, 2018. PMID: 29116467. DOI: $10.1007 / \mathrm{s} 10549-017-4562-4$
Received May 30, 2019

Revised June 28, 2019

Accepted July 4, 2019 